\title{
HAPPINESS AND COOPERATION
}

\author{
Luo Lu and Michael ARgYle \\ Department of Experimental Psychology, University of Oxford, South Parks Road, Oxford OX1 3UD, \\ England
}

(Received 4 December 1990)

\begin{abstract}
Summary-This study tested the hypothesis that cooperativeness is a causc of happiness. $114 \mathrm{Ss}$ were given a 36-item scale for cooperativeness, together with measures of happiness, extraversion, neuroticism, MHQ, COMQ, and other scales. This was repeated 6 months later. In a multiple regression analysis happiness at Time 2 was predicted by one factor of the cooperation scale which was interpreted as enjoying group leisure activities. This factor also discriminated $S$ s initially low in happiness who became happier; those who started happy and became less so were low on another dimension of cooperativeness-interpreted as enjoying joint activities at work. Happiness was also predicted by extraversion, (low) mental health (MHQ), and age (youth). Mental health correlated negatively with cooperation, but was not predicted by it; it had a two-directional relationship with happiness. The total cooperative score was predicted by extraversion and sex (female), and the cooperative over leisure factor was predicted by sex and social skills (COMQ).
\end{abstract}

\section{INTRODUCTION}

In a previous study (Argyle \& Lu, 1990a) we found that extraversion correlates with happiness partly because extraverts engage more in two kinds of social activity-teams and clubs, parties and dances. In a second paper, using a longitudinal design, we found that a further explanation for the greater happiness of extraverts is their assertiveness (Argyle \& Lu, 1990b). The findings of the first study suggest that the cooperative activities and hence the cooperative skills, of extraverts may be important for happiness.

What exactly is meant by "cooperation"? Dictionaries define it as "working together", social psychologists refer to shared or group goals. However these definitions emphasize rewards for joint work towards external rewards, and do not readily include some clearly cooperative activities, which cannot be performed alone, and where competition would often be irrelevant, like playing on a see-saw, dancing, making music, sexual intercourse, playing tennis and conversation.

There are perhaps four main classes of cooperation-joint task activity, social relationships, coordination over joint activities, communication and interaction.

Here is an attempt at a revised definition.

Cooperation: acting together, in a coordinated way at work, leisure, or in social relationships, in the pursuit of shared goals, the enjoyment of the joint activity, or simply furthering the relationship (Argyle, 1991).

Cooperation is found in all species of animals, in varying degrees, and several evolutionary models have been put forward to account for it. It follows from evolutionary theory that when a behaviour pattern serves long-term goals, shorter-term rewards will develop to provide appropriate motivation. For example, the joys of sex motivate reproduction. Cooperation of other kinds leads to the important goals of mutual help and social integration; it follows that there should be short-term rewards, that cooperation should lead to positive emotions and to happiness.

There is evidence that cooperation has certain positive consequences-mutual help and interpersonal attraction (Deutsch, 1949). Happiness and mental health are enhanced by companionship and social support; such social activities require cooperation and coordination of behaviour. Activities with friends are one of the main sources of joy (Scherer, Wallbott \& Summerfield, 1986). An important part of social support is cooperating in joint activities, being embedded in the activities of a social group. Examples are dancing, music, games, and other leisure activities of friends, and also, we shall suggest conversation. Research on helping behaviour finds that people often react negatively to being helped, and that cooperation produces more positive reactions (Worchel, 1979). 
In these cases there is no product, and the goal is the joint performance as an end in itself (Argyle, 1991). In the case of close relationships there does not appear to be any goal in the sense of seeking rewards, but rather both partners are seeking the goal of a close relationship, and are concerned with the welfare of the other (Clark \& Reis, 1989). For work there is division of labour, and job satisfaction is higher in cooperative groups (Argyle, 1991). Families can be regarded as groups devoted to biological cooperation over eating, child-rearing and mutual care. Conversation, and social interaction of all kinds, require a high degree of cooperation, in terms of the synchronising of utterances and keeping to social rules.

It was also expected that cooperation would benefit mental health, in view of the well-confirmed research showing the effects of social support on mental health. While support from an intimate has been shown to be important, recent studies have found that the social network is also important. This is supported by Rook (1987), who found that companionship had a greater effect on reducing loneliness, and enhancing psychological well-being, than emotional or instrumental support.

Individual differences research has so far not produced an accepted measure of cooperativeness. Ratings have been used for example for children playing. The Prisoners' Dilemma Game and other experimental games, offer a choice between cooperation, competition and sometimes altruism and individualism (Liebrand \& McClintock, 1988), but the validity of these games is very doubtful. No dimension of cooperativeness has been located, but in research on the "big five", "cooperative-negativistic" falls under the wider factor of "agreeableness" (Norman, 1963).

Some better-known scales and dimensions have been found to correlate with observed cooperative behaviour. Crandall's "social interest" scale is about being concerned about other people, including cooperation, sharing and helping. It comes very close to being a measure of cooperativeness. It correlates with cooperating in the Prisoners' Dilemma Game, ratings of cooperativeness by peers, and negatively with hostility and self-centredness (Crandall, 1980).

Social competence is often assumed to include cooperativeness, and lack of cooperativeness is regarded as unskilled (Dodge, 1985). McPhail (1967) compiled a list of common social problem situations encountered by adolescents. He found that the number of socially skilled solutions, where the needs of both sides were considered, increased rapidly between the ages of 12 and 17. Research on child language has obtained similar results. By the ages 14-15 most children use arguments to persuade others, in which they show how it is in the other's interests to do what is suggested.

Extraverts are cooperative in various ways, for example rating cooperative situations as likeable and rewarding (Wolfe \& Krasner, 1988). As we saw earlier, they take part in cooperative activities like teams and clubs. They are good at cooperating in ordinary social situations by asking questions, agreeing and paying compliments (Thorne, 1987).

Neuroticism is expected to be negatively related to cooperation, because neurotics tend to be egocentric, taking little interest in the concerns of others (Trower, Bryant \& Argyle, 1978).

Internal control is another possible predictor of cooperation. Those high on this variable are found to be happier, and believe that they can control events in which other people are involved (Phares, 1976). Such control is only possible with skilled cooperation.

Self esteem is a strong correlate of happiness. The interpersonal style of high esteem people is certainly distinctive, and it would well indicate the confidence and concern for others needed for cooperation.

"Collectivism" is a related concept, referring to the sharing of resources and outcomes with the immediate group, as found in Chinese culture (Hui \& Triandis, 1986). Individuals with high scores on collectivism have been found to be less lonely and to receive more social support (Triandis, Bontempo, Villareal, Asai \& Lucca, 1988).

There is evidence that women are on average more cooperative than men. Studies of children's play find that girls are more cooperative, boys more competitive (Knight $\&$ Chao, 1989). At the Prisoners' Dilemma Game women are less cooperative, but this is usually interpreted in terms of being less risky (Colman, 1982), and in social dilemmas with real money women are a little more cooperative (Stockard, Van de Kragt \& Dodge, 1988). Women have much higher scores on empathy (Eisenberg \& Miller, 1987). Women's groups are more egalitarian and cooperative. In groups which initially do not have leaders, men more often emerge as overall leaders, but women more often emerge as social leaders or "facilitators" (Eagley, 1990). In research on assertiveness 
it is also found that women are much more concerned with obligations to others. They think that it is important in assertive situations not to threaten others, to be friendly, and not to hurt others' feelings (Wilson, 1989).

Analysis of conversation finds that women are active in keeping conversation going, ask more questions, use more tag-questions, give more back-channel responses, and are more polite. Female social interactions appear to be directed towards the goals of friendship and social support (Smith, 1985; Argyle, 1991).

What exactly does cooperativeness consist of? There are probably several components.

(1) Competence - the ability to integrate the goals and ideas of different people, and find a common plan.

(2) Values-a preference for the cooperative mode, enjoying cooperation.

(3) Rules-believing that cooperation is the right way to do things.

These three aspects were incorporated in our 50-item questionnaire, which also covered 8 spheres of possible cooperation.

\section{METHOD}

\section{Subjects}

114 subjects from the Oxford Subject Panel took part in this study. The sample was composed of 42 males and 72 females, ages ranging from 18 to 65 , with a mean of 44.1 . There was no age difference between the two sexes.

\section{Procedure}

This study adopted a longitudinal design, and data were collected at two sessions with a 6 months interval from the above mentioned sample. The Time 1 questionnaires were sent out in March 1990, which contained measurements of happiness, mental health, cooperativeness, and various personality inventories (see the next section for a more detailed description). The Time 2 questionnaires were sent out in September 1990, which measured happiness, mental health, and cooperativeness again.

\section{Measurements}

(1) Happiness was measured by the Oxford Happiness Inventory (OHI) (Argyle, Martin \& Crossland, 1989).

(2) Mental health was measured by the Middlesex Hospital Questionnaire (MHQ) (Crown \& Crisp, 1979). The MHQ gives a total symptoms score and four subscale scores: depression, anxiety, obsessional symptoms, and somatic symptoms.

(3) Self-esteem was measured by Rosenberg's self evaluating scale (1965).

(4) Social skills were measured by the COMQ (Sarason, Sarason, Hacker \& Basham, 1985).

(5) Assertiveness was measured by Gambrill Assertion Inventory (Gambrill \& Richey, 1975). This scale gives two indices of assertiveness: the discomfort an individual feels in various situations which demand assertion, and the probability of response in an assertive fashion. The original scale is scored in reverse, however, for simplicity: in this paper the higher scores on both indices indicate more assertiveness.

(6) Extraversion and neuroticism were measured by the E and N scales in the EPQ (Eysenck \& Eysenck, 1975).

(7) Internal locus of control was measured by Paulhus and Christie's Control Personality Inventory (1981).

(8) Cooperativeness was measured by a new scale especially devised for this study. The psychometric procedure of devising this scale requires some detailed description.

The scale construction began by examining the existing measures of psychological constructs relevant to cooperation, e.g. collectivism. Fifty original items were extracted from various scales in the literature, or made up to reflect general and specific attitudes towards cooperation and joint activities (Argyle, 1991). These items were initially classified into the domains Leisure, Leadership, 
Friends, Family, Education, Clubs, Work, and Committees. Half of the 50 items were in favour of cooperation, and the other half against.

This item pool was administered to the research sample of 114 adults. Respondents rated themselves on each item according to a 5-point scale ranging from "Strongly agree" to "Strongly disagree". The scale was re-administered 6 months later to the same sample.

Using these data, item-to-scale correlations were computed for all the items. Fourteen items that had low correlations $(P<0.05)$ with the total scale were dropped. The final version of the Cooperativeness Scale is given in the Appendix.

\section{RESULTS}

\section{Analyses of cooperativeness}

Responses on the final version of the 36-item Cooperativeness Scale were subjected to a factor analysis with varimax rotation. The factor analysis was performed on Time 1 and Time 2 data separately. However the factor structures yielded were similar on the two data sets. This cross validation could be taken as evidence of internal structural reliability of the scale.

The original domains disappeared, and four factors emerged, accounting for $36.7 \%$ (Time 1 ) and $38 \%$ (Time 2) of the total variance. They can be labelled as: Factor 1 (11 items): "Managing conflicts/negotiation"; Factor 2 (12 items): "Decision making"; Factor 3 (6 items): "Joint activities/doing things together"; Factor 4 (7 items): "Group productivities/working together". The internal consistency (alpha) coefficients for the scales administered at Time 1 and Time 2 ranged from 0.55 to 0.77 . The test-retest reliability over 6 months was also acceptable (see Table 1). The 36 -items scale at this stage still consisted of roughly half positive and half negative items.

In all the further analyses, the total score of the 36 items and the four factor scores will be used. There was some preliminary validity data on the Cooperativeness Scale. Table 2 presents correlations between scores of cooperativeness and various psychological measurements used in this study.

Cooperativeness correlated positively with general index of social skills measured by COMQ, especially in aspects of managing conflicts/negotiation (Factor 1), and joint activities/doing things together (Factor 3). Cooperativeness also correlated positively with self-esteem, especially in domains of decision making (Factor 2), whereas this aspect of cooperativeness correlated negatively with neuroticism. It seems that different aspects of cooperativeness are linked with different psychological qualities and skills. Evidence of convergent validity also came from correlations between cooperativeness and extraversion, since extraverts are generally regarded as having superior social skills and enjoying joint activities.

However, the Cooperativeness Scale is not just a general index of positive or desirable traits and skills. It showed no relationship with internal locus of control $(0.08)$ or assertiveness $(0.17$ n.s. $)$. The divergence between cooperativeness and assertiveness is conceptually interesting, since it reveals that although cooperation undoubtedly requires social skills, assertive skills alone are not sufficient.

When we examine the predictive validity of the Cooperativeness Scale, we found that cooperativeness correlated positively with happiness, but not with mental health. On the one hand, this evidence fits nicely with the hypothesized linkage between cooperativeness and well-being; on the other hand, it reflects the fact that there are a lot of psychiatrically normal people around who are "loners".

Finally, the Cooperativeness Scale also revealed a clear sex difference: women tended to be more cooperative than men. There was an interesting age difference as well. Where cooperation in decision making is concerned, younger people were more cooperative than their older counterparts. This might reflect changes in social values over the generations.

In summary, the reliability of the Cooperativeness Scale was acceptable, and the validity was generally congruent with our conceptualization of the cooperativeness construct, and the existing literature on relevant topics outlined in the introduction section. Nevertheless, more detailed work on this new scale needs to be carried out in the future. 
Table 1. Factor analysis on The Cooperativeness Scale

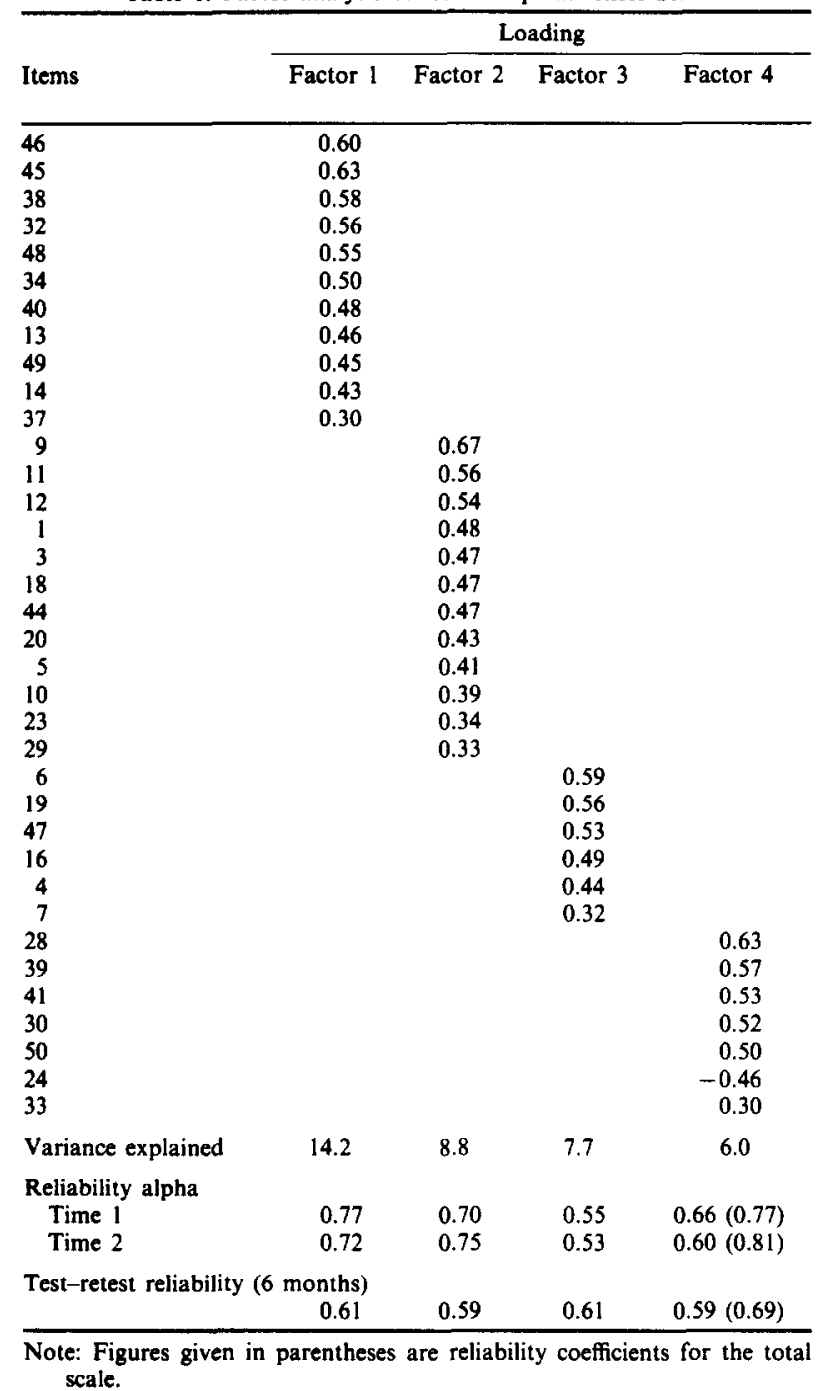

\section{Causes of happiness and mental health}

Since measurements of happiness and mental health were administered twice, at the beginning and end of this study, correlations between baseline (Time 1) and latent (Time 2) measures of each variable were computed first. The Pearson correlation coefficient for happiness over 6 months was $0.65(P<0.001)$, and that for mental health was $0.75(P<0.001)$. Furthermore, there was no difference detected on $t$ tests between either pair of baseline and latent measures. It seems both

Table 2. Correlations between The Cooperativeness Scale and other measures

\begin{tabular}{|c|c|c|c|c|c|}
\hline & Total & Factor 1 & Factor 2 & Factor 3 & Factor 4 \\
\hline Sex & $0.25^{*}$ & 0.09 & $0.17^{*}$ & $0.23^{*}$ & 0.18 \\
\hline Age & -0.14 & -0.15 & $-0.21^{*}$ & 0.14 & -0.14 \\
\hline OHI & $0.26+$ & 0.11 & 0.17 & $0.25 \dagger$ & $0.22 *$ \\
\hline MHQ & -0.11 & -0.04 & -0.18 & -0.01 & -0.01 \\
\hline Social skills & $0.29+$ & $0.23 \dagger$ & 0.11 & $0.26 \dagger$ & 0.18 \\
\hline Self-esteem & $0.19^{\prime \prime}$ & 0.17 & $0.24 \dagger$ & 0.05 & -0.03 \\
\hline $\begin{array}{l}\text { Assertiveness } \\
\text { (discomfort) }\end{array}$ & 0.18 & 0.15 & 0.13 & 0.02 & 0.11 \\
\hline $\begin{array}{l}\text { Assertiveness } \\
\text { (response) }\end{array}$ & 0.17 & 0.13 & 0.09 & 0.05 & 0.14 \\
\hline Extraversion & $0.31 \ddagger$ & $0.21^{*}$ & 0.15 & $0.23^{*}$ & $0.30 \ddagger$ \\
\hline Neuroticism & -0.14 & $-0.20^{*}$ & -0.09 & -0.02 & -0.03 \\
\hline Control & 0.08 & 0.08 & 0.03 & 0.10 & -0.04 \\
\hline
\end{tabular}

Sex was coded as $1=$ male, $2=$ female.

$=P<0.05, \dagger=P<0.01 . t=P<0.001$. 
Table 3. Correlations between happiness, mental health and other measures

\begin{tabular}{lcc}
\hline Variables & Happiness & Mental health \\
\hline Sex & 0.10 & 0.08 \\
Age & $-0.22^{*}$ & 0.16 \\
Social skills & $0.33 \ddagger$ & -0.18 \\
Self-esteem & $0.39 \ddagger$ & $-0.41 \ddagger$ \\
Assertiveness (discomfort) & 0.12 & -0.17 \\
Assertiveness (response) & $0.19^{*}$ & 0.02 \\
Extraversion & $0.47 \ddagger$ & $-0.21^{*}$ \\
Neuroticism & $-0.26 \dagger$ & $0.54 \ddagger$ \\
Control & $0.42 \ddagger$ & $-0.28 \ddagger$ \\
Cooperativeness (total) & $0.26 \dagger$ & -0.11 \\
Factor 3 & $0.25 \dagger$ & -0.01 \\
Factor 4 & $0.22^{*}$ & -0.01 \\
Happiness & & $-0.47 \ddagger$ \\
\hline
\end{tabular}

Sex was coded as $1=$ male, $2=$ female.

$*=P<0.05,+=P<0.01, \ddagger=P<0.001$.

levels of happiness and psychological symptoms were very stable over time. Therefore, in all the further correlation analyses, scores on personality (including cooperativeness) and skills measures were those taken at Time 1, and happiness and mental health were those taken at Time 2.

Table 3 presents the pattern of correlations between demographic variables, personality factors, social skills, and happiness and mental health.

First, there was no correlation between sex and either happiness or mental health. However, there was a negative correlation between age and happiness: younger people tend to be happier in this sample. Second, the personality measures all correlated with happiness. Self-esteem, extraversion, internal locus of control, and cooperativeness had positive relations with happiness, while neuroticism had a negative relation. The directions of correlations were all reversed for (poor) mental health, though cooperativeness had no relation with symptoms. Third, general social skills and the response index of assertiveness correlated positively with happiness. However, skills measurements did not correlate with mental health. Finally, there was a high negative correlation between happiness and (poor) mental health.

Following these correlation patterns, two sets of multiple regression analyses were performed to predict happiness and mental health. To predict latent happiness (Time 2) from all its correlates, a stepwise multiple regression was first performed. Age, concurrent mental health (Time 2), extraversion, and cooperativeness (Factor 3 ) all emerged as significant predictors. In order to explore their independent contributions toward happiness, a hierarchical multiple regression analysis then followed. Baseline happiness (Time 1) was entered into the regression equation first, followed by these identified predictors. Even after controlling for the baseline happiness, effects of age, mental health, extraversion and cooperativeness in regard of joint activities, on happiness were still significant. Results of the hierarchical regression are presented in the upper half of Table 4.

To predict latent mental health (Time 2) from all its correlates, a stepwise multiple regression was first performed. Concurrent happiness (Time 2) and neuroticism emerged as significant predictors. In order to explore their independent contributions toward mental health, a hierarchical multiple regression analysis then followed. Baseline mental health (Time 1) was entered into the regression equation first, followed by these identified predictors. After controlling for the baseline

Table 4. Predicting latent happiness and mental health after controlling for their

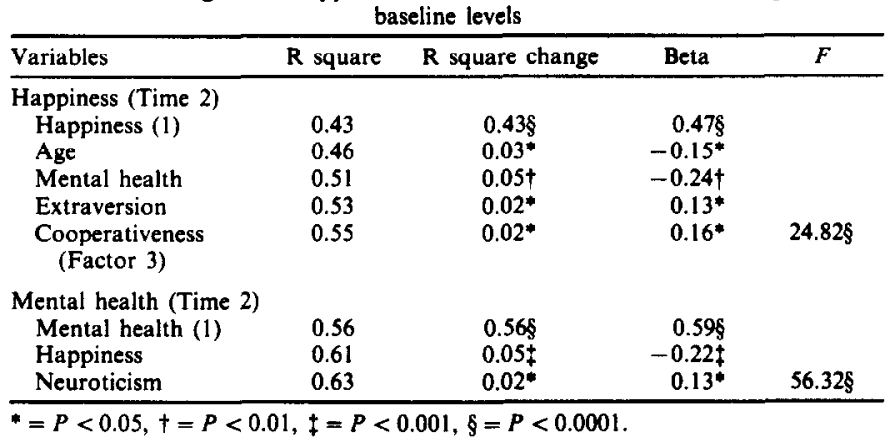




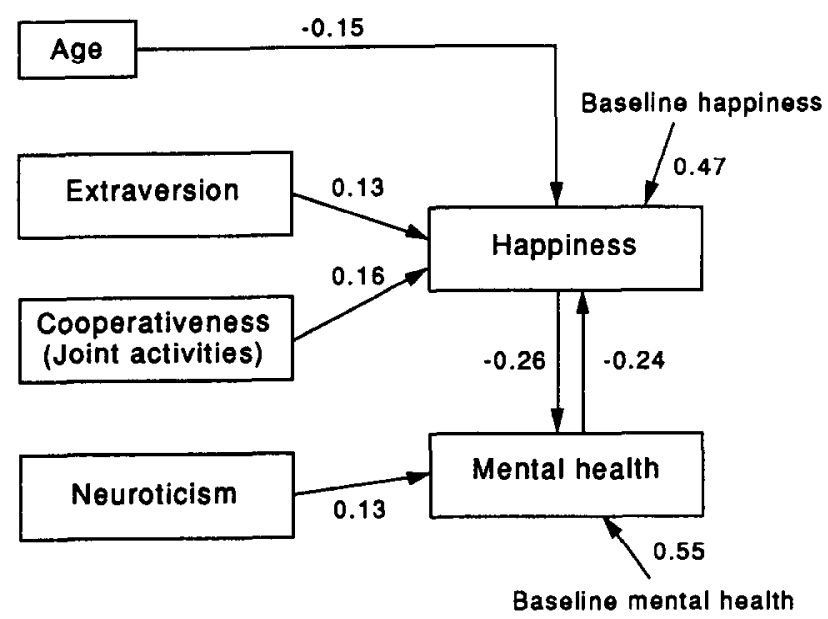

Note: All coefficlents are significant

Fig. 1. Causes of happiness and mental health.

mental health, effects of happiness and neuroticism on mental health were still significant. Results of the hierarchical regression are presented in the lower half of Table 4.

The results so far suggested that after partialling out the baseline cffects, the relationship between happiness and mental health was bi-directional; and each could be independently predicted by a set of psychological variables. These relationships are presented graphically in Fig. 1.

To carry further the study on happiness, another method of analysis was adopted. The entire group was divided into four subgroups, according to the group mean scores on happiness in Times 1 and 2. The Hi-Hi Group consisted of people who were stably happy, i.e. those who scored above the mean at both Times 1 and 2 . The Lo-Lo Group consisted of people who were stably unhappy, i.c. those scorcd below the mean at both Times 1 and 2. The Hi-Lo Group was the risk group, consisting of people who scored above the mean at Time 1 but fell below the mean at Time 2 . The Lo-Hi Group was the prognostic group, consisting of people who scored below the mean at Time 1 but rose above the mean at Time 2. By comparing the Hi-Hi Group with the Hi-Lo Group, we should be able to identify the risk factors to happiness. Similarly, by comparing the Lo-Lo Group with the Lo-Hi Group, we should be able to identify the prognostic factors to happiness. Significant $t$ tests results on these two analyses are given in Table 5 .

Symptoms of depression, extraversion, and cooperativeness over group productivities/working together, seemed to distinguish the Hi-Hi Group from the Hi-Lo Group. Therefore, more

Table 5. Subgroup comparisons to identify risk factors and prognostic

\begin{tabular}{|c|c|c|c|c|c|}
\hline \multirow[b]{3}{*}{ Variables } & \multicolumn{4}{|c|}{ Risk factors } & \multirow[b]{3}{*}{$t$} \\
\hline & \multicolumn{2}{|c|}{$\mathrm{Hi}-\mathrm{Hi}$} & \multicolumn{2}{|c|}{ Hi-Lo } & \\
\hline & Mean & SD & Mean & SD & \\
\hline Depression & 3.02 & 1.76 & 4.50 & 2.51 & $2.21^{*}$ \\
\hline Extraversion & 14.34 & 4.26 & 11.50 & 3.42 & $1.81 \dagger$ \\
\hline \multirow{3}{*}{$\begin{array}{l}\text { Cooperativeness } \\
\text { (Factor 4) }\end{array}$} & 22.02 & 4.22 & 19.50 & 3.34 & $1.77 \dagger$ \\
\hline & \multicolumn{4}{|c|}{ Prognostic factors } & \\
\hline & \multicolumn{2}{|c|}{ Lo-Lo } & \multicolumn{2}{|c|}{ Lo-Hi } & \\
\hline Control & 84.31 & 11.40 & 94.64 & 16.17 & $2.51^{*}$ \\
\hline $\begin{array}{l}\text { Cooperativeness } \\
\text { (Factor 3) }\end{array}$ & 16.93 & 4.00 & 19.73 & 3.07 & $2.16^{*}$ \\
\hline
\end{tabular}


symptoms of depression, introversion, and less cooperativeness over working with other people might be risky to happiness.

Internal locus of control and cooperativeness over joint activities/doing things together seemed to distinguish the Lo-Lo Group from the Lo-Hi Group. Therefore, Internal locus of control and cooperativeness over doing things with other people might enhance one's happiness.

\section{Causes of cooperativeness}

Following the correlation pattern presented in Table 2, a series of regression analyses were performed to predict cooperativeness and its four components from their correlates. Results are shown in Table 6.

First, extraversion and sex predicted overall cooperativeness. Women were more cooperative than men in general. Second, social skills predicted aspects of managing conflicts/negotiation in cooperation. Third, self-esteem and sex predicted cooperation concerning decision making. People with high self-esteem and women were more willing to cooperate on decision making. Fourth, social skills and sex predicted cooperation on joint activities. People with better social skills and women were more willing to cooperate in joint activities. Fifth, extraversion predicted cooperation on group productivities. These relationships are graphically presented in Fig. 2.

In a study which involved multiple psychological variables, it is necessary to check the intercorrelations between these variables before we can make sense of the complicated results. Table 7 gives these intercorrelations. As we can see, these psychological constructs were all closely correlated, with a few exceptions. Cooperativeness did not correlate with assertiveness or internal locus of control. The intercorrelations between assertiveness and social skills, self-esteem, extraversion, neuroticism, and internal locus of control might explain the lack of contribution from assertiveness in results so far presented. Contributions of other psychological variables might have included those variances originally accounted for by assertiveness.

\section{Sex differences}

Finally, $t$ tests were performed to compare men and women on personality, skills, happiness and mental health. Significant results are presented in Table 8.

There was no sex difference on either happiness or mental health. While women tend to be socially more skilled and more cooperative over joint activities, they also tend to be more neurotic than men.

\section{DISCUSSION}

The theoretical implications of the results related to reliability and validity of the Cooperativeness Scale have already received elaborated discussion at the beginning of the Results section. We first wanted to establish the existence of a cooperativeness dimension. The 36 items did not produce a general factor, but instead 4 orthogonal ones. However Cronbach's alpha was 0.77 at Time 1 and 0.81 at Time 2; we therefore used both the total score and the 4 factor scores in the analyses. The total cooperation measure appears to have some psychological reality: it is significantly higher

Table 6. Predicting cooperativeness from its correlates

\begin{tabular}{|c|c|c|c|c|}
\hline Variables & R square & $\mathbf{R}$ square change & Beta & $F$ \\
\hline \multicolumn{5}{|l|}{ Total scale } \\
\hline Extraversion & 0.10 & $0.10 \ddagger$ & $0.28+$ & \\
\hline Sex & 0.14 & $0.04^{*}$ & $0.21^{*}$ & $8.81 \pm$ \\
\hline \multicolumn{5}{|c|}{ Managing conflicts } \\
\hline Social skills & 0.05 & $0.05 \dagger$ & $0.23^{+}$ & $6.28+$ \\
\hline \multicolumn{5}{|l|}{ Decision making } \\
\hline Self-esteem & 0.06 & $0.06 \dagger$ & $0.25+$ & \\
\hline Sex & 0.09 & $0.03^{*}$ & $0.19^{*}$ & $5.36 \ddagger$ \\
\hline \multicolumn{5}{|l|}{ Joint activities } \\
\hline Social skills & 0.07 & $0.07 \dagger$ & $0.22 *$ & \\
\hline Sex & 0.10 & $0.03^{*}$ & $0.19^{*}$ & $6.08+$ \\
\hline \multicolumn{5}{|c|}{ Group productivities } \\
\hline Extraversion & 0.09 & $0.09+$ & $0.30_{+}^{+}$ & 10.868 \\
\hline
\end{tabular}

Sex was coded as $1=$ male, $2=$ female.

$*=P<0.05, \dagger=P<0.01, \ddagger=P<0.001, \S=P<0.0001$. 


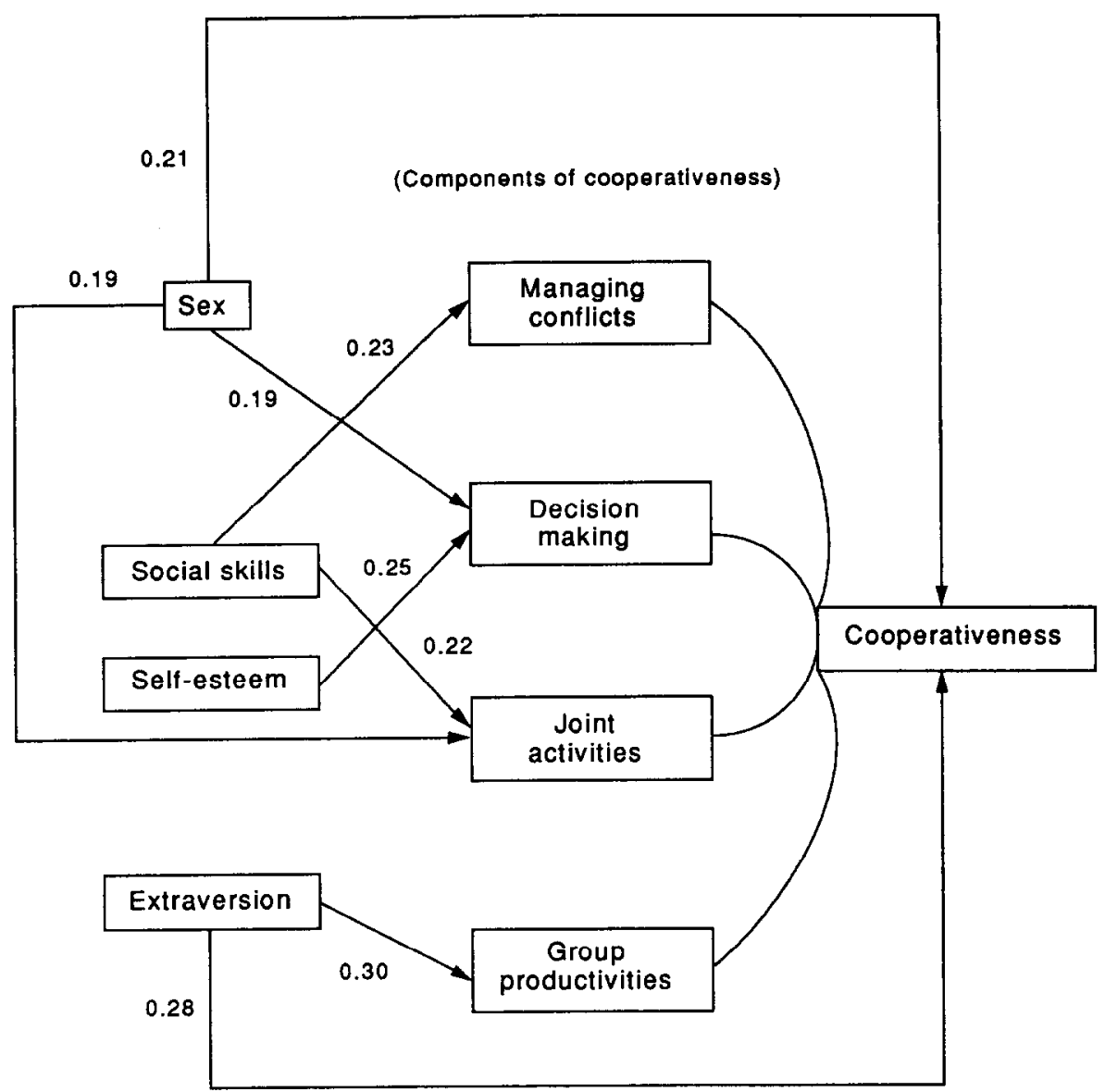

Note : All coefficients are significant

Fig. 2. Causes of cooperativeness.

for women as predicted, it correlates with happiness, social skills and extraversion, but does not correlate with mental health, assertiveness or internal control. However in the more demanding statistical analyses in the present study it dropped out while two of the factors stayed in-III (joint activities) and IV (working together). We are not sure how seriously to take our 4-factors of cooperativeness. They did appear clearly in a sample of 114 , and had distinctive patterns of correlation with other variables, so it looks as if there are something like these components of cooperativeness.

Table 7. Intercorrelations between personality factors and social skills measures

\begin{tabular}{|c|c|c|c|c|c|c|c|}
\hline Variables & 2 & 3 & 4 & 5 & 6 & 7 & 8 \\
\hline \begin{tabular}{l} 
Social skills \\
Self-esteem \\
Extraversion \\
Neuroticism \\
Control \\
Cooperativeness \\
Assertiveness \\
\multicolumn{1}{c}{ (discomfort) } \\
Assertiveness \\
(response)
\end{tabular} & $0.49 t$ & $\begin{array}{l}0.75 t \\
0.43 t\end{array}$ & $\begin{array}{l}-0.27 \dagger \\
-0.46_{+}^{+} \\
-0.29 \dagger\end{array}$ & $\begin{array}{r}0.55 \ddagger \\
0.54 \ddagger \\
0.56 \ddagger \\
-0.29 \ddagger\end{array}$ & $\begin{array}{c}0.29 \dagger \\
0.19^{*} \\
0.31 \ddagger \\
-0.14 \\
0.08\end{array}$ & $\begin{array}{r}0.33 \ddagger \\
0.26 \dagger \\
0.25 \dagger \\
-0.31 \ddagger \\
0.23^{*} \\
0.17\end{array}$ & $\begin{array}{r}0.34 \ddagger \\
0.18^{*} \\
0.38 \ddagger \\
-0.20^{*} \\
0.21 * \\
0.16 \\
0.63 \ddagger\end{array}$ \\
\hline
\end{tabular}


Table 8 . Sex differences on personality factors and social skills

\begin{tabular}{lrrrrrr}
\hline \multirow{2}{*}{ Variables } & \multicolumn{2}{c}{ Male } & & \multicolumn{2}{c}{ Female } & \\
\cline { 2 - 3 } & Mean & SD & & Mean & SD & $t$ \\
\hline Social skills & 25.3 & 6.7 & & 27.9 & 6.0 & $2.14^{*}$ \\
Neuroticism & 10.1 & 5.5 & 12.3 & 5.0 & $2.17^{*}$ \\
Cooperativeness & 101.5 & 15.2 & & 109.0 & 13.1 & $2.72 \dagger$ \\
Factor 3 & 17.3 & 3.6 & & 19.2 & 4.0 & $2.47 \dagger$ \\
\hline$*=P<0.05, \dagger=P<0.01$. & & & & &
\end{tabular}

Factor I had no correlation with happiness; this factor consists of items about friction in groups, like "Social clubs have a lot of internal friction and clashes between individuals". This may reflect lack of cooperative skills, or perhaps experience of difficult groups. Factor II also had no correlation with happiness; it consists of items about decision-taking and leadership, such as "It is usually best if one partner in a relationship is the boss". Factor III came out most clearly related to happiness and contained the following items:

"Most forms of leisure are better done in groups."

"Family members always enjoy doing things together."

"Decisions taken by groups are better than those taken by individuals."

"It is more fun doing things with friends than alone."

"Team members usually pull together, rather than seeking individual glory."

"Group leisure activities, like choirs, orchestras, theatricals and folk dancing, are often tiresome and irritating."

The main hypothesis was that cooperativeness at Time 1 would predict happiness at Time 2 . The multiple regression found that happiness was quite stable over a 6-month interval $(r=0.66)$, but the cooperativeness Factor III was also a significant predictor, as was age, extraversion and mental health.

A second analysis was made of the sub-groups of subjects whose happiness increased or decreased over the 6 months. The original highs who became less happy were initially less cooperative on Factor IV (working together), less extraverted, and more depressed. Those who were initially low on happiness who became happier were initially more cooperative on Factor III and higher on internal control. So Factor IV is a risk factor for the happy, while Factor III can help the unhappy. Factor III items are all about enjoying doing leisure activities-together in groups and with friends. They are not so much about cooperative skills, but rather about a cooperative attitude. Factor IV is similar but is about joint activities at work, e.g. "Involvement in joint projects at work is very satisfying". As a check, all the four factors were correlated with the P scale which was given with the $\mathrm{E}$ and $\mathrm{N}$ scales in the EPQ. However, none of the correlations was significant.

It was hypothesized that lack of cooperativeness would predict poor mental health. The two mental health measures (MHQ and N) had low negative correlations with cooperation; Factor I correlated $-0.20(P<0.05)$ with $\mathrm{N}$; but cooperation did not predict mental health in the regression analyses. However mental health and happiness had a two-way relationship, each predicting the other, as shown in Fig. 1, and depression was a risk factor for happy people as shown above.

What are the causes of cooperativeness? The total score on cooperativeness is predicted only by extraversion and sex (women more). The separate factors had different predictors: Factor III is predicted by social skills and sex, Factor IV by extraversion. Factor III is the factor which came out most strongly linked to happiness. It is about having a positive attitude to engaging in group leisure activities with friends. This sounds very similar to extraversion, but the correlation with extraversion was only 0.23 and extraversion did not predict it, so it is evidently something different. It is partly an attitude, but partly perhaps a skill too, the skill needed to enjoy group activities.

Acknowledgements - We are grateful to the Leverhulme Foundation for financial support.

\section{REFERENCES}

Argyle (1991). Cooperation. London: Routlege.

Argyle, M. \& Lu, L. (1990a). The happiness of extraverts. Personality and Individual Differences, 11, $1011-1017$.

Argyle, M. \& Lu, L. (1990b). Happiness and social skills. Personality and Individual Differences, 11, 1255-1261. 
Argyle, M., Martin, M. \& Crossland, J. (1989). Happiness as a function of personality and social encounters. In Forgas, J. P. \& Innes, J. M. (Eds) Recent advances in social psychology: An international perspective. North Holland: Elsevier.

Clark, M. \& Reis, H. T. (1989). Interpersonal processes in close relationships. Annual Review of Psychology, 39, 602-672.

Colman, A. (1982). Cooperation and competition in humans and animals. Wokingham: Van Nostrand.

Crandall, J. E. (1980). Adler's concept of social interest: theory, measurement and implications for adjustment. Journal of Personality and Social Psychology, 39, 481-495.

Crown, S. \& Crisp, A. (1979). Crown-Crisp experimental index. London: Hodder and Stoughton.

Deutsch, M. (1949). A theory of cooperation and competition. Human Relations, 2, 129-139. An experimental study of the effects of cooperation and competition upon group processes. Human Relations, 2, 199-231.

Dodge, K. A. (1985). Facets of social interaction and the assessment of social competence in children. In Schneider, B. H. et al. (Eds) Children's Peer Relations: Issues in Assessment and Intervention. New York: Springer-Verlag.

Eagley, A. (1990). Gender and leadership style: a meta-analysis. Psychological Bulletin, 108, 233-256.

Eisenberg, N. \& Miller, P. A. (1987). The relation of empathy to prosocial and related behaviors. Journal of Personality and Social Psychology, 52, 91-119.

Eysenck, H. J. \& Eysenck, S. B. G. (1975). Manual for the Eysenck Personality Questionnaire. London: Hodder and Stoughton.

Gambrill, E. D. \& Richey, C. A. (1975). An assertion inventory for use in assessment and research. Behavior Therapy, 6, $547-549$.

Hui and Triandis (1986).

Knight, G. P. \& Chao, C.-C. (1989). Gender differences in the cooperative, competitive, and individualistic values of children. Motivation and Emotion, 13, 125-141.

Liebrand, W. B. G. \& McClintock, C. G. (1988). The ring measure of social values: a computerized procedure for assessing individual differences in information processing and social value orientation. European Journal of Personality, 2 , 217-230.

McPhail, P. (1967). The development of social skills in adolescents. (Unpublished). Oxford University Department of Education.

Norman, W. T. (1963). Toward an adequate taxonomy of personality attributes: replicated factor structure in peer nomination personality ratings. Journal of Abnormal and Social Psychology, 66, 574-588.

Paulhus, D. \& Christie, R. (1981). Sphere of control: an interactionist approach to assessment of perceived control. In Lefcourt, H. M. (Ed.) Research with the locus of control construct, Vol. 1. New York: Academic Press.

Phares, E. J. (1976). Locus of control. In London, H. \& Exner, J. E. (Eds) Dimensions of personality. New York: Wiley.

Rook, K. S. (1987). Social support versus companionship: effects on life stress, loneliness, and evaluation by others. Journal of Personality and Social Psychology, 52, 1132-1147.

Rosenberg, M. (1965). Society and the adolescent self-image. Princeton: Princeton University Press.

Sarason, B. R., Sarason, I. G., Hacker, T. A. \& Basham, R. B. (1985). Concomitants of social support: social skills, physical attractiveness, and gender. Journal of Personality and Social Psychology, 49, 469-480.

Scherer, K. R., Wallbott, H. G. \& Summerfield, A. B. (1986). Experiencing emotions. Cambridge: Cambridge University Press.

Smith, P. M. (1985). Language, the Sexes and Society. Oxford: Blackwell.

Stockard, J., Van de Kragt, A. J. C. \& Dodge, P. J. (1988). Gender roles and behavior in social dilemmas: are there sex differences in cooperation and its justification? Social Psychology Quarterly, 51, 154-163.

Thorne, A. (1987). The press of personality: a study of conversation between introverts and extraverts. Journal of Personality and Social Psychology, 53, 718-726.

Triandis, H. C., Bontempo, R., Villareal, M. J., Asai, M. \& Lucca, N. (1988). Individualism and collectivism: cross-cultural perspectives on self-ingroup relationships. Journal of Personality and Social Psychology, 54, 323-328.

Trower, P., Bryant, B. \& Argyle, M. (1978). Social Skills and Mental Health. London: Methuen.

Wilson, L. K. (1989). Assertion and its social context. Ph.D. Thesis, University of Queensland.

Wolfe, R. N. \& Krasner, J. A. (1988). Type versus trait: extraversion, impulsivity, sociability, and preferences for cooperative and competitive activities. Journal of Personality and Social Psychology, 54, 864-871.

Worchel, S. (1979). Cooperation and the reduction of intergroup conflict: some determining factors. In Austin, W. G. \& Worchel, S. (Eds) The social psychology of intergroup relations. Monterey, Calif.: Brooks/Cole.

\section{A PPENDIX}

\section{The Cooperativeness Scale}

All statements to be rated on the scale: totally agree-totally disagree.

Leisure

(1) It is usually difficult for quite different people to collaborate in teams.

(2) People perform better at sports when members of a team than when competing as individuals.

(3) I enjoy individual games more than team ones.

(4) Team members usually pull together, rather than seeking individual glory.

(5) Other members of leisure groups are often difficult to get on with.

(6) Most forms of leisure are better done in groups.

(7) Group leisure activities, like choirs, orchestras, theatricals and folk dancing, are often tiresome and irritating.

(8) People ought to spend their spare time together with their family or friends.

Leadership

(9) It is difficult for leaders to take decisions if their subordinates are allowed to participate in them.

(10) Better decisions are taken if subordinates participate.

(11) It is a bore trying to take account of the views of subordinates.

(12) Leaders ought to make up their own minds, and not waste too much time consulting people. 


\section{Friends}

(13) To go on a trip with friends makes one less free and mobile.

(14) There is often friction between friends because they want to do different things.

(15) Friends ought to be very concerned about each other's wishes.

(16) It is more fun doing things with friends than alone.

(17) Friends can do more things together than alone.

\section{Family}

(18) It is usually best if one partner in a relationship is the boss.

(19) Family members always enjoy doing things together.

(20) It isn't possible to allow children a full say in decisions affecting them.

(21) In a good relationship all possessions are shared.

(22) Husbands and wives should have an equal say in what happens.

(23) It is difficult to prevent friction in families.

\section{Education}

(24) Too much time is spent in school on team "projects".

(25) An important part of education is learning to get on with others.

(26) Competition is the best way to teach children in school.

(27) I never share my ideas or materials with other students.

(28) I like to cooperate with other students over academic work.

(29) When I am among my colleagues/classmates, I do my own thing without minding about them.

(30) Classmates' assistance is indispensable to getting a good result in college.

(31) Most children find project work rather difficult.

\section{Clubs}

(32) Social clubs often have a lot of internal friction and clashes between individuals.

(33) It is fun taking part in running a social club.

(34) Social clubs are the best way to spend leisure.

(35) Social clubs usually work very efficiently.

(36) People ought to help to run social clubs they belong to

\section{Work}

(37) It is often difficult working together with other people.

(38) It is more enjoyable to be responsible for your own efforts at work.

(39) Involvement in joint projects at work is very satisfying.

(40) It is often more productive to work on your own.

(41) Team work is always the best way of getting results

(42) It is essential to recognize individual achievement at work.

(43) Success is the most important thing in life.

(44) If the group is slowing me down, it is better to leave it and work alone.

\section{Committees}

(45) It is difficult to arrive at an agreed decision, in groups.

(46) Negotiations and committees are often difficult and tense.

(47) Decisions taken by groups are better than those taken by individuals.

(48) A lot of time is wasted arguing about things in committees.

(49) I love spending time on committees.

(50) All decisions should be taken by committees rather than by individuals.

Note: Items 2, 8, 15, 17, 21, 22, 25, 26, 27, 31, 35, 36, 42, 43 were dropped in later analyses because of their low item-to-scale correlations. 